\title{
$\checkmark$ Research Square \\ Impact of pollutant as selection pressure on conjugative transfer of dioxin-catabolic plasmids harbored by Rhodococcus sp. strain p52
}

\section{Gang Zhao}

Shandong University

Yanan Wu

Shandong University

\section{Xu Wang}

Shandong University

\section{Meng Chen}

Shandong University

\section{Li Li ( $\nabla 13953153037 @ 163 . c o m)$}

Shandong University https://orcid.org/0000-0002-2457-2332

\section{Research Article}

Keywords: Dioxins, Conjugative transfer, Activated sludge, Selection pressure, Catabolic-plasmid, Genetic bioaugmentation, Bioremediation

Posted Date: March 30th, 2021

DOl: https://doi.org/10.21203/rs.3.rs-326904/v1

License: (9) (1) This work is licensed under a Creative Commons Attribution 4.0 International License. Read Full License

Version of Record: A version of this preprint was published at Environmental Science and Pollution Research on August 5th, 2021. See the published version at https://doi.org/10.1007/s11356-021-156829. 


\section{Abstract}

Plasmid-mediated bioaugmentation has potential application in the cleanup of recalcitrant environmental pollutants. In this study, we examined the influence of various contaminants (in different categories or different amounts) as a selection pressure on the transfer of catabolic plasmids within an activated sludge bacteria community bioaugmented with Rhodococcus sp. strain p52 harboring pDF01 and pDF02. The distinguishable genera of transconjugants were isolated under the stresses of phenanthrene, dibenzothiophene, and dibenzo- $p$-dioxin. The difference in genomic $\mathrm{G}+\mathrm{C}$ content $(5.0 \sim 27.5 \%)$ between transconjugants and strain p52 indicated the transfer of the catabolic plasmids crossing phylogenetic boundaries. The specific removal rates in activated sludge reactors for phenanthrene, dibenzothiophene, and dibenzo- $p$-dioxin were elevated in turn. The three contaminants exerted different degrees of influence on the activated sludge bacteria bearing the catabolic plasmids. The highest proportion of transconjugants was detected in the reactor fed with dibenzo- $p$-dioxin. Additionally, as dibenzo- $p$-dioxin from 10 to $80 \mathrm{mg} / \mathrm{L}$ was fed into the reactors, the proportion of transconjugants increased. Film mating tests demonstrated that the plasmid transfer frequency varied among recipients under the contaminant stresses of phenanthrene, dibenzothiophene, and dibenzo-p-dioxin. Our study provides a characterization of the recalcitrant contaminants as a selection pressure that can modulate catabolic plasmid transfer during genetic bioaugmentation for the removal of contaminants.

\section{Introduction}

The escalating rate of industrialization has led to the release of various recalcitrant organic compounds into the environment during the past century. Among these compounds, persistent organic pollutants comprise one of the most notorious groups, as they include polychlorinated dibenzodioxins, polychlorinated dibenzofurans, and polychlorinated biphenyls (Kulkarni et al. 2008; Urban et al. 2014). With stable structures and high hydrophobicity, they are resistant to biodegradation in natural environments (lyer et al. 2016). There are obstacles to the efficient removal of these pollutants by bacteria in treatment engineering facilities or by in situ remediation systems (Herrero et al. 2015). Fortunately, some excellent microbial degraders have been equipped with evolved catabolic pathways (Chakraborty and Das 2016; Kolvenbach et al. 2014; Sharma et al. 2018) and can be exploited to reinforce the indigenous microbiota that facilitate bioaugmentation (Carlos et al. 2017; Herrero et al. 2015). Bioaugmentation is operated in two nuanced approaches: inoculating efficient degrading strains to dominate the degradation of pollutants (cell bioaugmentation) or introducing mobile genetic elements (MGEs) to disseminate catabolic ability to indigenous bacterial populations (genetic bioaugmentation) (Carlos et al. 2017). Due to the frequent failure of the inoculated cells during interactions with biological and non-biological environmental factors, the latter has significant advantages over the former (Carlos et al. 2017; Herrero and Stuckey 2015). In most cases, the key genes responsible for degrading the recalcitrant pollutants are located on MGEs, including plasmids, transposons, integrons, and genomic islands or phages (Top et al. 2002; Tsuda et al. 1999; Van et al. 2001). In particular, conjugative or mobilizable plasmids are the major carriers during the horizontal transfer of genes, and they have played 
a major role in genetic bioaugmentation (Bathe 2004; Carlos et al. 2017). The selection of donor-plasmid pairs is a priority in the application of genetic bioaugmentation. A highly transferrable plasmid with a broad host range and encoding catabolic pathways for target pollutants are prerequisites for genetic bioaugmentation application. Additionally, robust donor adaptation to the environment (e.g., reactors or contaminated sites) is preferable, though independent of the donor's long-term survival. After introducing the plasmid-harboring donor into an indigenous bacterial community, the proportions of catabolic plasmid (or catabolic pathway) bearers in the bacterial community seem to determine the removal efficiency of the target pollutant (Top and Springael 2003). Environmental conditions, including biotic and abiotic factors, can influence genetic bioaugmentation. These factors include the morphological and physiological characteristics of donor cells, the ratio and phylogenetic relatedness of donors and recipients, temperature, $\mathrm{pH}$, and the features of contaminants (Alderliesten et al. 2020; Carlos et al. 2017; Shintani et al. 2017; Stallwood et al. 2005).

During contaminant bio-treatment, the contaminant itself plays a critical role in plasmid-mediated genetic bioaugmentation. On the one hand, the recalcitrant organic compounds can provide nutrients for the growth of the bacterial cells that have acquired catabolic plasmids. Thus, the plasmid bearers gain a unique niche with competitive advantages over the bacteria without plasmids. On the other hand, the recalcitrant contaminants exert toxic effects on the bacterial cells and trigger a cascade of responses in the cells to ameliorate the situation (Zhao et al. 2019). In this sense, the contaminants serve as a selection pressure to promote the catabolic plasmid-bearing population in the bacterial community, like a driver of genetic bioaugmentation. However, the expression and replication of plasmids require energy and resources of the host cells, and thus catabolic plasmids also carry a burden (i.e., fitness cost) to the bearer (Millan et al. 2014). As a result, the plasmid-bearing cells within a bacterial population are prone to be replaced by the nonbearing cells in the absence of selection pressure (Ikuma and Gunsch 2012a). Consequently, selection pressure is required to maintain the ratio of transconjugants in the bacterial community. During contaminant treatment by microorganisms, continuously present selection pressure modulates catabolic plasmid transfer and confers a fitness advantage to the hosts (i.e., transconjugants) (Fan et al. 2019). Though attention has been paid to the influence of some contaminants as selection pressures during catabolic plasmid transfer (Bouma and Lenski 1988; Ikuma and Gunsch 2012a; Millan and Maclean 2017), much remains unclear, especially the action modes of the contaminants. For example, there is little information concerning the impacts of the category and strength of the selection pressure (deriving from different contaminants) on catabolic plasmid transfer compared to the flourishing studies on the influence of antibiotics on horizontal transfer of resistance genes. Thus, it is worthwhile to focus attention on the effects of contaminants as a selection pressure on catabolic plasmid transfer.

We previously isolated Rhodococcus sp. strain p52, which can utilize dibenzofuran as the sole carbon and energy source (Peng et al. 2013). This strain contains two gene clusters (dfdA1A2A3A4 and $d b f A 1 A 2$ ) encoding two angular dioxygenases located on two plasmids, pDF01 and pDF02 (Peng et al. 2013), that can initiate the dihydroxylation of a wide range of aromatic compounds such as dibenzofuran, dibenzo-p-dioxin, dibenzothiophene, and phenanthrene (Kasuga et al. 2013; Peng et al. 
2013). The plasmids pDF01 and pDF02 contain the catabolic genes for an integrated dioxin degradation pathway. The catabolic plasmids can be conjugative transferred into a broad range of bacterial strains (Sun et al. 2017). Genetic bioaugmentation of activated sludge with the plasmids harbored by strain p52 enhanced the removal of dibenzofuran in laboratory-scale sequencing batch reactors. The catabolic plasmids pDF01 and pDF02 have shown potential application in genetic bioaugmentation for contaminant remediation (Ren et al. 2018). The purpose of the present study is to examine the effect of contaminants as a selection pressure on genetic bioaugmentation with the catabolic plasmids. To achieve this, we examined the conjugative transfer of the catabolic plasmids under various selection pressures (different categories or different amounts of contaminant) within an activated sludge bacteria community bioaugmented with strain p52. We investigated the host range and monitored the transfer of the plasmids under the different selection pressures. Additionally, we demonstrated the influence of recipient species on the plasmid transfer under different selection pressures via film mating tests. Our study will provide a characterization of the recalcitrant contaminants as a selection pressure to modulate catabolic plasmid transfer during genetic bioaugmentation for the removal of contaminants.

\section{Materials And Methods}

\section{Activated sludge reactors setup}

A series of laboratory-scale activated sludge reactors was set up. The working volume of the reactor was $1 \mathrm{~L}$, and the inner diameter and the length of the reactor were $90 \mathrm{~mm}$ and $300 \mathrm{~mm}$, respectively. An air diffuser was installed at the bottom of each reactor, and the aeration rate was $0.8 \mathrm{~L} / \mathrm{min}$. The activated sludge (taken from the aeration tank of the waste treatment plant of Qingdao Campus, Shandong University) was aerated for a week to exhaust carbon sources. The initial mixed liquid suspended solids (MLSS) concentration of each reactor was $3.6 \mathrm{~g} / \mathrm{L}$, and the experimental temperature and $\mathrm{pH}$ were controlled at $25^{\circ} \mathrm{C}$ and $6.0-8.0$, respectively. The hydraulic retention time was $24 \mathrm{~h}$, operating in a sequencing batch mode (each cycle was $5 \mathrm{~min}$ for influent, $20 \mathrm{~min}$ for precipitation, $5 \mathrm{~min}$ for effluent, and the remaining time for aeration. The volume exchange ratio was $50 \%$ ). The synthetic wastewater was fed into the reactors in the composition $0.462 \mathrm{~g} / \mathrm{L} \mathrm{NH}_{4} \mathrm{Cl}, 0.108 \mathrm{~g} / \mathrm{L} \mathrm{KH}_{2} \mathrm{PO}_{4}, 0.540 \mathrm{~g} / \mathrm{L} \mathrm{MgSO}_{4} \cdot 7 \mathrm{H}_{2} \mathrm{O}$, $0.216 \mathrm{~g} / \mathrm{L} \mathrm{KCl}, 0.066 \mathrm{~g} / \mathrm{L} \mathrm{CaCl}_{2}, 0.006 \mathrm{~g} / \mathrm{L}$ yeast extract, and $1.8 \mathrm{~mL} / \mathrm{L}$ trace element solution. The trace element solution consisted of $0.240 \mathrm{~g} / \mathrm{L} \mathrm{MnCl}_{2} \cdot 4 \mathrm{H}_{2} \mathrm{O}, 0.240 \mathrm{~g} / \mathrm{L} \mathrm{ZnCl}_{2}, 0.300 \mathrm{~g} / \mathrm{L} \mathrm{H}_{3} \mathrm{BO}_{3}, 0.060 \mathrm{~g} / \mathrm{L} \mathrm{KI}$, $0.300 \mathrm{~g} / \mathrm{L} \mathrm{Na} \mathrm{MoO}_{4} \cdot 2 \mathrm{H}_{2} \mathrm{O}, 0.116 \mathrm{~g} / \mathrm{L} \mathrm{CoCl}_{2} \cdot 6 \mathrm{H}_{2} \mathrm{O}$, and $0.060 \mathrm{~g} / \mathrm{L} \mathrm{CuSO}_{4} \cdot 5 \mathrm{H}_{2} \mathrm{O}$. The $\mathrm{pH}$ value of the synthetic wastewater was around 7.0 (Van Loosdrecht et al. 2016). Dibenzo-p-dioxin, dibenzothiophene, and phenanthrene were dissolved in ethanol as stock solutions with a final concentration of $20 \mathrm{~g} / \mathrm{L}$. To test the strength of selection pressure, dibenzo-p-dioxin in a concentration gradient of $10,20,40$, and 80 $\mathrm{mg} / \mathrm{L}$ was supplemented to the synthetic wastewater. To test the category effect of selection pressure, dibenzo- $p$-dioxin, dibenzothiophene, and phenanthrene with concentrations of $40 \mathrm{mg} / \mathrm{L}$ were supplemented to the synthetic wastewater. In the control reactor, sodium acetate trihydrate was supplemented to the synthetic wastewater instead of the contaminant. Each test was repeated at least three times. The COD concentration of influent in the reactor was about $2400 \mathrm{mg} / \mathrm{L}$, and the ratio of COD, 
$\mathrm{N}\left(\mathrm{NH}_{4}{ }^{+}-\mathrm{N}\right)$ and $\mathrm{P}\left(\mathrm{PO}_{4}{ }^{3}-\mathrm{P}\right)$ was 100:5:1. The reactors for the experimental groups were inoculated with $10 \mathrm{~mL}$ of strain p52 cell suspension to a final cell density of $10^{6}-10^{7} \mathrm{CFU} / \mathrm{mL}$ in the reactor. Strain p52 cell suspension was prepared as follows: strain p52 was pre-cultured in a $250-\mathrm{mL}$ Erlenmeyer flask containing $50 \mathrm{~mL} \mathrm{LB}$ medium and shaken in an incubator at $30^{\circ} \mathrm{C}$ and $180 \mathrm{rpm}$ for 24 hours. The cells were centrifuged and washed with carbon-free mineral salts medium (MSM) three times, then resuspended in the $\mathrm{MSM}\left(\mathrm{OD}_{600}=1\right)$.

To determine the concentrations of residual contaminants and MLSS in the reactors, $50 \mathrm{~mL}$ and $100 \mathrm{~mL}$ of the mixed-liquor samples were taken from the reactor at the end of each cycle. The sampling for analysis was carried out within the first two days in this study. Extraction and analysis of the residual contaminants were conducted as described in a previously study (Ren et al. 2018). The MLSS concentration was determined according to standard methods (American Public Health Association 1998). The specific removal rate for each contaminant was calculated as follows:

$$
\text { Specific removal rate }((\mathrm{mg} / \mathrm{d}) / \mathrm{g} \text { MLSS })=\frac{(I-R) / t}{M L S S} \text {, }
$$

where / and $R$ are the initial concentration and residual concentration of the contaminant, respectively, and $t$ is the time for removal. Data are shown as the means of the triplicate tests.

\section{Transconjugants acquisition}

The mixed-liquor samples were taken from the reactors and spread on the selective plates prepared from dibenzofuran-supplemented carbon-free MSM at the end of each operation cycle. After being cultured at $30^{\circ} \mathrm{C}$ for four days, the colonies (mostly white round colonies) with morphological characteristics different from strain p52 (orange-red round colonies) were chosen for further confirmation by colony PCR as described by Ren et al. (2018). The primers used in this study are shown in Table 1. The proper sized PCR products checked by electrophoresis were sequencing-analyzed for further confirmation.

Simultaneously, transconjugants were identified by amplification and sequencing analysis of the $16 \mathrm{~S}$ rRNA gene for Blast searches against the NCBI nucleotide database.

\section{DNA extraction and quantitative polymerase chain reaction (qPCR) analysis}

At the end of each operation cycle, $10 \mathrm{~mL}$ mixed-liquor samples were taken from each reactor for total DNA extraction using a soil DNA isolation kit (Omega Biotek, Inc., Norcross, GA) according to the manual. The qPCR was conducted as previously described using the iCycler thermocycler (BIO-RAD), and absolute copy numbers of target DNA fragments were calculated based on the obtained Ct value and the standard curve (Yun et al. 2006). The qPCR primers information is shown in Table 1. In this study, the copy numbers of $d f d A$ and $d b f A$ fragments were determined to evaluate the total number of plasmid-harboring cells (including transconjugants and strain p52). Meanwhile, the copy number of the specific fragment targeting an intergenic spacer region (ISR) between the 16S and 23S rRNA genes of strain p52 was 
determined to evaluate the total number of strain p52. And the copy number of the 16S rRNA gene of the total bacteria in the mixture was determined. The ratio of transconjugants was assessed based on the absolute copy number of the target DNA detected by qPCR, and the calculation formula was as follows:

$$
\text { Ratio of transconjugants }=\frac{I_{t}-R_{t} \times \mathrm{A}}{R_{o} \times \mathrm{A}}
$$

where $I_{t}$ is the copy number of $d f d A$ (located on pDF01) or $d b f A$ (located on pDF02) fragment within $2 \mathrm{~d}$; $R_{t}$ and $R_{o}$ are the copy numbers of strain p52 ISR within $2 \mathrm{~d}$ and the initial copy number of strain p52 ISR, respectively. A is the copy number of pDF01 or pDF02 per cell of Rhodococcus sp. strain p52; these are 1 and 4 , respectively. Data are shown as the means of the triplicate tests.

Table 1 Primers for PCR in this study

\begin{tabular}{|c|c|c|c|}
\hline Targets & Oligonucleotide sequence ( $5^{\prime}$ to $\left.3^{\prime}\right)$ & Amplicon size (bp) & Sources \\
\hline$d b f A 1$ & F: GCTCATGACCAGCATTAGCG & 1800 & Peng et al. 2013 \\
\hline (conventional PCR) & R: GGGCCTCAGAAGAAGATGGAG & & \\
\hline$d f d A 1$ & F: GCAGTCTGTACCGACGCT & 1070 & Peng et al. 2013 \\
\hline (conventional PCR) & R: GAGTGCGACGGGATGGAC & & \\
\hline \multirow[t]{2}{*}{$d b f R T 1$ (qPCR) } & F: TACAGCAACAACGGCGATCT & 160 & Ren et al. 2018 \\
\hline & R: TCGAAGGCCAGGTCCAGATA & & \\
\hline \multirow[t]{2}{*}{$d f d R T 3$ (qPCR) } & F: CCGGTATAACCTGTCTCGGC & 210 & Ren et al. 2018 \\
\hline & R: CGGTAGTCTCCTACACCGGA & & \\
\hline ISR p52 & F: gccagagaccgattgtccc & 193 & Ren et al. 2018 \\
\hline (qPCR) & R: aagaaaactgatttccttgtttcgc & & \\
\hline \multirow[t]{2}{*}{ 16S rRNA gene (qPCR) } & F: atggctgtcgtcagct & 352 & Ren et al. 2018 \\
\hline & R: acgggcggtgtgtac & & \\
\hline
\end{tabular}

\section{Filter mating experiments}

Transconjugants isolated from activated sludge were subjected to continuous passage until the plasmids were lost. Then, the strains without plasmids were used as the recipients, and strain p52 was used as a donor to perform filter mating experiments under different selection pressures. Briefly, the donor and recipient strains were inoculated into $250-\mathrm{mL}$ Erlenmeyer flasks containing $50 \mathrm{~mL}$ LB medium and cultivated at $30^{\circ} \mathrm{C}$ under shaking conditions at $180 \mathrm{rpm}$ for $24 \mathrm{~h}$. Then, the donor and the recipient cells were harvested, adjusted to the $\mathrm{OD}_{600} \approx 0.6-0.8$ (each about $10^{8} \mathrm{CFU} / \mathrm{ml}$ ) and mixed at a ratio of 1:1, washed three times with carbon-free MSM, and finally resuspended with the MSM. After that, the mixed 
cells were layered onto a sterilized $0.22 \mu \mathrm{m}$ filter membrane on MSM agar medium supplemented with different contaminants (dibenzo- $p$-dioxin, dibenzothiophene, and phenanthrene at $40 \mathrm{mg} / \mathrm{L}$ ) or dibenzo- $p$ dioxin at different concentrations $(10,20$, and $80 \mathrm{mg} / \mathrm{L})$ to test the effect of selection pressure. The same protocol using a filter membrane on the carbon-free MSM agar medium supplemented with $40 \mathrm{mg} / \mathrm{L}$ dimethyl sulfoxide (DMSO) served as a control. The mixed cells on filter membranes were incubated at $30^{\circ} \mathrm{C}$ for $24 \mathrm{~h}$. Finally, the cells were washed off from the filter membrane with the MSM and spread on a dibenzofuran supplemented MSM agar plate (selective plate) and incubated at $30^{\circ} \mathrm{C}$ for four days. The transconjugants were confirmed as described above. The frequency of catabolic plasmids transferred under various selection pressures was indicated as the ratio of the final amount of transconjugants to the initial amount of donor bacteria strain p52.

\section{Statistical Analysis}

Statistical analysis was performed using SPSS version 26.0. The differences between means compared to controls were analyzed by one-way analysis of variance (ANOVA). Statistical significance was accepted at the $p<0.05$ level. Data are shown as the means of triplicate experiments.

\section{Results}

\section{Isolation of transconjugants in activated sludge fed with different contaminants}

Transconjugants were isolated from activated sludge during contaminant removal. These transconjugants were confirmed to harbor two catabolic plasmids, pDF01 and pDF02 (Fig. 1). A total of nine genera-affiliated transconjugants were isolated, and the general features of different genera of transconjugants are listed in Table 2. The distinguishable genera of transconjugants were isolated under the stresses of different contaminants. In particular, the transconjugants belonging to all nine genera were isolated during treatment of dibenzo- $p$-dioxin. Transconjugants belonging to Arthrobacter and Klebsiella were isolated from activated sludge during treatment of each of the three contaminants. The average $\mathrm{G}+\mathrm{C}$ contents of the transconjugants were compared to the donor strain according to the GenBank genome database. The average genomic $\mathrm{G}+\mathrm{C}$ content of most species of transconjugants differed from that of the strain p52 by more than $5.0 \%$, and the difference in genomic $\mathrm{G}+\mathrm{C}$ content between Acinetobacter and strain p52 was $27.5 \%$. The results indicated a relatively broad host range of the catabolic plasmids.

The degradation of pollutants mainly depended on the combined effect of strain p52 and the transconjugants in activated sludge that had acquired pDF01 and pDF02. As shown in Fig. 2, the specific removal rates of the activated sludge for phenanthrene, dibenzothiophene, and dibenzo- $p$-dioxin rose in turn. In contrast, the activated sludge bacteria in the control could not efficiently degrade these compounds. This indicated that bioaugmentation of the reactors with strain $p 52$ enhanced the degradation of different contaminants. 
Table 2

Transconjugant affiliated genera isolated from activated sludge during treatment of different contaminants

\begin{tabular}{|c|c|c|c|}
\hline $\begin{array}{l}\text { Transconjugant } \\
\text { affiliated genus }\end{array}$ & $\begin{array}{l}\text { Percentage of detection (detected } \\
\text { colonies/the total transconjugant } \\
\text { colonies } \times 100 \% \text { ) }\end{array}$ & $\begin{array}{l}\text { Average G } \\
+ \text { C\% of } \\
\text { genome }\end{array}$ & $\begin{array}{l}\text { Isolating sources (target } \\
\text { contaminants fed into } \\
\text { reactors) }\end{array}$ \\
\hline \multirow[t]{3}{*}{ Arthrobacter } & \multirow[t]{3}{*}{$24.87 \%$} & \multirow[t]{3}{*}{65.2} & Phenanthrene \\
\hline & & & Dibenzothiophene \\
\hline & & & Dibenzo-p-dioxin \\
\hline Rhodococcus & $16.03 \%$ & 64.6 & Dibenzo-p-dioxin \\
\hline Pseudomonas & $19.88 \%$ & 60.8 & Dibenzo-p-dioxin \\
\hline \multirow[t]{2}{*}{ Corynebacterium } & \multirow[t]{2}{*}{$13.27 \%$} & \multirow[t]{2}{*}{60.7} & Dibenzothiophene \\
\hline & & & Dibenzo-p-dioxin \\
\hline Agrobacterium & $2.21 \%$ & 59.3 & Dibenzo-p-dioxin \\
\hline \multirow[t]{3}{*}{ Klebsiella } & \multirow[t]{3}{*}{$20.99 \%$} & \multirow[t]{3}{*}{57.0} & Phenanthrene \\
\hline & & & Dibenzothiophene \\
\hline & & & Dibenzo-p-dioxin \\
\hline \multirow[t]{2}{*}{ Enterobacter } & \multirow[t]{2}{*}{$1.10 \%$} & \multirow[t]{2}{*}{55.2} & Dibenzothiophene \\
\hline & & & Dibenzo-p-dioxin \\
\hline Citrobacter & $1.10 \%$ & 51.9 & Dibenzo-p-dioxin \\
\hline \multirow[t]{2}{*}{ Acinetobacter } & \multirow[t]{2}{*}{$0.55 \%$} & \multirow[t]{2}{*}{40.3} & Dibenzothiophene \\
\hline & & & Dibenzo- $p$-dioxin \\
\hline
\end{tabular}

\section{Catabolic plasmid transfer within sludge bacteria community under the stress of different contaminants}

Previous studies have demonstrated that dibenzo-p-dioxin, dibenzothiophene, and phenanthrene are all substrates for the dioxygenases encoded on catabolic plasmids (Kasuga et al. 2013; Peng et al. 2013). The three recalcitrant compounds were fed into reactors to test the effect of different contaminants as positive stresses on catabolic plasmid transfer. As activated sludge bacteria could not efficiently utilized these compounds, the MLSS of the reactor gradually decreased over time (data not shown). The amount of the total activated sludge bacteria was monitored (Fig. 3a). The numbers of the total bacteria in all reactors increased from day 1 to day 2 , and the increases were far greater in the reactors fed with phenanthrene and dibenzothiophene than in the control. Simultaneously, the numbers of strain p52 in all 
bioaugmented reactors increased significantly after one day and were higher than in the control (Fig. 3b), indicating the adaptability and robustness of the introduced strain p52 in the reactors with the contaminants. As shown in Figs. 3c and 3d, the contaminants exerted different degrees of influence on the activated sludge bacteria bearing the catabolic plasmids. The highest proportion of the transconjugants $\left(1.74 \times 10^{-1}\right)$ was detected in the reactor fed with dibenzo-p-dioxin within two days followed by the treatment of dibenzothiophene, and the least was observed with phenanthrene. The proportions of transconjugants in all reactors fed with the contaminants increased with time, by about one order of magnitude from the first to second days. In addition, different ratios for pDF01 and pDF02 were observed even if the difference in their copy numbers within a cell was deducted, indicating the distinct dynamics of the two catabolic plasmids in sludge bacterial cells.

\section{Catabolic plasmid transfer under the stress of dibenzo- $p$-dioxin at different concentrations}

To examine the strength of selection pressure on catabolic plasmid transfer, dibenzo-p-dioxin of different concentration was fed into the reactors. The amount of total sludge bacteria and strain p52 in reactors fed with different concentrations of dibenzo- $p$-dioxin was monitored by qPCR. As shown in Fig. 3a, the amount of total sludge bacteria and strain $p 52$ increased in the reactors fed with dibenzo-p-dioxin. Unlike the preference of strain p52 for dibenzo- $p$-dioxin at high concentrations, the low concentration $(10 \mathrm{mg} / \mathrm{L})$ was more favorable to the total sludge bacteria compared with the control. Specifically, the amount of sludge bacteria increased significantly on day 2 compared to that on day 1, except in the reactor containing $10 \mathrm{mg} / \mathrm{L}$ dibenzo-p-dioxin. A similar trend was observed for the number of strain p52 (Fig. 3b). The proportions of transconjugants were evaluated (Fig. 4c \& 4d). As dibenzo-p-dioxin concentrations were supplemented from 10 to $80 \mathrm{mg} / \mathrm{L}$, the proportions of transconjugants gradually increased within the experimental period. The results indicated that the concentration of dibenzo-p-dioxin, in other words, the strength of selection pressure, promoted the transconjugant proportion in the sludge bacterial community. Additionally, the transfer frequency of pDF02 was disproportionate to that of pDF01, with the exclusion of the difference in their copy numbers within a cell, indicating that transconjugants containing only one catabolic plasmid might be present in the sludge bacterial community. Accordingly, only one catabolic plasmid could be detected by PCR amplification of the target genes on the catabolic plasmids in some transconjugants (data not shown).

\section{Influence of recipients on catabolic plasmid transfer under contaminant stress}

To further understand the effects of selection pressure on catabolic plasmid transfer, film mating was conducted to demonstrate the influence of the recipients. Nine catabolic plasmid-free bacterial strains isolated from the activated sludge served as recipients mating with the donor strain $\mathrm{p} 52$. Under the contaminant stresses of phenanthrene, dibenzothiophene, and dibenzo- $p$-dioxin, the plasmid transfer frequency varied among different donor-recipient mating pairs (Fig. 5a). However, the transfer frequencies did not reflect the taxonomic relatedness between the recipient and the donor. For example, the frequency of plasmids transferred from strain $\mathrm{p} 52$ to the Rhodococcus sp. recipient was relatively low, in contrast to that using Pseudomonas sp. as a recipient. In addition, different contaminants exerted varied selection pressures on catabolic plasmid transfer. The transfer frequency between most donor-recipient pairs was 
in an ascending order under the selective stresses of phenanthrene, dibenzothiophene, and dibenzo- $p$ dioxin at $40 \mathrm{mg} / \mathrm{L}$. However, the frequency under the different contaminant stresses using Acinetobacter sp. and Enterobactersp. as recipients was not in accord with that of other recipients, indicating the distinctive responses of the recipients. Additionally, the frequency of the catabolic plasmids transferred between individual donor-recipient pairs under dibenzo-p-dioxin at different concentrations was measured (Fig. 5b). The plasmid transfer frequency increased for all recipient strains with the increase of dibenzo- $p$ dioxin concentration from $10 \mathrm{mg} / \mathrm{L}$ to $40 \mathrm{mg} / \mathrm{L}$. Meanwhile, almost no colonies were detectable on the selective plates in the control with the treatment of DMSO instead of dibenzo-p-dioxin. However, when the concentration of dibenzo- $p$-dioxin increased to $80 \mathrm{mg} / \mathrm{L}$, the transfer frequency of the catabolic plasmids varied among different recipients. For most recipient strains, except Corynebacterium sp., Klebsiella sp., and Rhodococcus sp., the transfer frequency decreased when the dibenzo-p-dioxin concentration was increased to $80 \mathrm{mg} / \mathrm{L}$. In contrast, transconjugants of Arthrobacter sp. were only detected for dibenzo- $p$ dioxin above $80 \mathrm{mg} / \mathrm{L}$. The results underscored the distinctive effects of selection pressure for different recipient strains.

\section{Discussion}

Plasmid-mediated catabolic gene transfer has played an important role in bacterial evolution, and at present the process contributes to the efficient cleanup of emerging recalcitrant pollutants in the environment (Urban et al. 2014). In the present study, we characterized the influence of contaminants as selection pressures on the transmission of catabolic plasmids within the bacterial community. Both the category and amount of the contaminants modulated catabolic plasmid transfer, and thus influenced the efficient removal of the contaminants.

For application to genetic bioaugmentation, we examined the conjugative transfer of catabolic plasmids in the activated sludge reactor, a model system in bio-treatment engineering. The abundant activated sludge bacterial species included an ample recipient pool that facilitated profiling the host range of the catabolic plasmids. In previous studies, pDF01 and pDF02 have shown a relatively broad range of hosts and were often transferred concomitantly (Ren et al. 2018; Sun et al. 2017). We isolated transconjugants belonging to nine genera from activated sludge during treatment of dibenzo- $p$-dioxin, dibenzothiophene, and phenanthrene. Furthermore, conjugative transfer of pDF01 and pDF02 occurred between bacteria with distant phylogenetic relationships, as indicated by the significant differences in their genomic $G+C$ content. There are biological obstacles to obtaining genes from donor bacteria with excessively different G + C contents (Popa and Dagan 2011). Our results demonstrated the possibility of horizontal transfer of catabolic genes crossing phylogenetic boundaries in the environment. Horizontal transfer of the accessary genes to distantly related microorganisms has received considerable attention, since beneficial to bacteria may yet afflict humans (Qiu et al. 2012). As inferred from the diverse catabolic pathways present in the microbial community (Kim et al. 2018; Monika et al. 2021), horizontal gene transfer provides a promising solution for amelioration of emerging pollutants in natural environments. 
Though selection pressure plays critical roles during genetic bioaugmentation (Digiovanni et al. 1996), it is difficult to distinguish the actual influence on plasmid lateral transfer or on the growth of transconjugants (in other words, vertical transmission of the plasmids). Studies have shown that the presence of selection pressure is not a prerequisite when conjugative transfer of plasmids occurs (Guo et al. 2015). To date, there is fragmentary information on selection pressure modulating the conjugation process. Limited knowledge of the mechanisms of selection pressure acting on the conjugation process follows from the arguments of selection pressure promoting the spread of antibiotic resistance genes $\mathrm{Pu}$ et al. 2021). Selection pressures such as those imposed by antibiotics or heavy metals can cause global cellular responses that indirectly stimulate conjugation or particularly induce an SOS response, resulting in directly up-regulating the expression of conjugation machinery genes (Beaber et al. 2004; Lopatkin et al. 2016; Zhang et al. 2018). Unlike the controversial opinion that selection pressure influences the conjugation process, researchers are prone to regard the selection pressure as an advantage for the competitive growth of transconjugants under positive selection (Andersson and Hughes 2014; Top et al. 2002). It is reasonable to assume that the catabolic genes carried by the plasmids confer the plasmidbearer the ability to utilize the contaminants for growth. Hence the presence of selection pressure promotes the propagation of transconjugants.

Regarding the effect of selection pressure on plasmid transfer, the different methods used to detect transconjugants could influence the results (Wang et al. 2020). In the present study, the proportion of transconjugants in the sludge bacteria was measured by qPCR analysis. When we calculated the frequency of plasmid transfer, the values according to the results of qPCR were higher than those measured by the spread plate method (data not shown). Actually, the results from distinct detection methods reflected different perspectives. In general, the host range of a plasmid is usually narrower than the transfer host range (plasmids can be transferred by conjugation) and wider than the stably maintained (long-term) host range (Shintani et al. 2014; Suzuki et al. 2010). In the present study, transconjugants were detected after the donor had been introduced into the activated sludge for at least $24 \mathrm{~h}$; otherwise, the donor was mixed with the recipient after $24 \mathrm{~h}$ during filter mating. The distinguishable ratios of transconjugants detected herein involved contributions from the transfer frequency of the catabolic plasmids and the proliferation of transconjugants. Nevertheless, the selection for the phenotypes of catabolic plasmid-bearing transconjugants proceeded differently under the individual contaminant stresses. On the one hand, the category of contaminants selected distinguishing genera of the plasmid hosts, although permissive recipients belonging to Arthrobacter and Klebsiella were present. On the other hand, the category and amounts of contaminants influenced the proportions of plasmidbearing bacteria in the community. In particular, under the stress of dibenzo- $p$-dioxin, relatively abundant hosts were observed, and the highest numbers of plasmid-bearing bacteria were detected. Here, we dissected the dynamics of contaminant selection between the conjugation step and transconjugant propagation. As has been reported previously, chemicals can trigger an increase in intracellular reactive oxygen species (ROS) along with increases of membrane permeability that facilitate the process of conjugative plasmid transfer (Han et al. 2019; Lu et al. 2020; Wang et al. 2018; Zhang et al. 2019). In fact, we have detected increases of the ROS levels in activated sludge bacteria during treatment of different 
contaminants (Fig. SM-1, online resource), and the elevation of the membrane permeability was indicated by extracellular lactate dehydrogenase level of the sludge bacteria under the stress of different contaminants (Fig. SM-2, online resource). The rise in ROS level is linked to triggering the SOS response (Han et al. 2019), merging into the global regulation network in cells, which may up-regulate genes on plasmids responsible for conjugation (Baharoglu et al. 2010; Banuelos-Vazquez et al. 2018; Butala et al. 2009; Fornelos et al. 2016; Jones and Holland 1985). Therefore, the contaminants as a selection pressure might promote the conjugation process. Further studies are needed to elucidate the contaminant triggered-regulation in the donor and recipient cells during the conjugation process. In the present study, dibenzo-p-dioxin, dibenzothiophene, and phenanthrene were all degradable substrates following the pathways encoded by the catabolic plasmids (Kasuga et al. 2013; Peng et al. 2013). Thus, after acquisition of the plasmids, the transconjugants in the sludge bacteria gained the ability to utilize the contaminants. Under the stresses of the different contaminants, the resulting highest proportion of the transconjugants occurred with the relatively high removal rate of dibenzo-p-dioxin; this could be attributed to the propagation of the transconjugants by utilizing the contaminants as carbon and energy sources, although this does not exclude the possible distinction of conjugation efficiency under the different stresses. Similarly, the stronger the dibenzo- $p$-dioxin concentration in the reactor, the greater the amounts of carbon and energy sources available to support the growth of transconjugants, thereby leading to higher proportions of the transconjugants. Herein, the contaminants as selection pressures could provide necessary nutrients for the sludge bacteria that carried the catabolic plasmids, thereby conferring benefits to the host sufficient to offset the fitness cost.

The utilization of different contaminants seems vital to plasmid-bearing bacteria. There are two intrinsic factors that distinguish the catabolism of the different contaminants, aside from the optimal environmental conditions for efficient degradation. One is the property of the catabolic enzymes encoded by the plasmids, which determines the kinetics of the degradation of different contaminants (Carlos et al. 2017; Ikuma et al. 2012b). This could explain the distinct effect of the contaminant category on the proportions of transconjugants in the activated sludge. The other is the plasmid host features that may vary in the chemotactic activity and transmembrane transport of the contaminant, as well as in the regulation, transcription, and expression of the genes on the plasmids. This in turn accounts for individual recipient performance differing in acquiring, and afterward propagating catabolic plasmids under contaminant stresses. Therefore, the effect of contaminants as a selection pressure varies with the catabolic plasmids and the recipients.

\section{Declarations}

Ethics approval and consent to participate Not applicable.

Consent for publication Not applicable.

Availability of data and materials The datasets used and/or analysed during the current study are available from the corresponding author on reasonable request. 
Competing interests The authors declare that they have no competing interests.

Authors' contributions Gang Zhao conducted the experiments, prepared the figures, and wrote main manuscript text. Yanan Wu, Xu Wang and Meng Chen edited the manuscript and proofread the full manuscript. Li Li prepared the main framework of the overall experiments and rearranged the contents. All authors read and approved the final manuscript.

\section{References}

1. Alderliesten JB, Duxbury SJN, Zwart MP, de Visser JAGM, Stegeman A, Fischer EAJ (2020) Effect of donor-recipient relatedness on the plasmid conjugation frequency: a meta-analysis. BMC Microbiol 20(1):135. https://doi.org/10.1186/s12866-020-01825-4

2. Aly HAH, Huu NB, Wray V, Junca H, Pieper DH (2008) Two angular dioxygenases contribute to the metabolic versatility of dibenzofuran-degrading Rhodococcus sp. strain HA01. Appl Environ Microbiol 74(12):3812-3822. https://doi.org/10.1128/AEM.00226-08

3. American Public Health Association (1998) Standard methods for the examination of water and wastewater. Washington. DC

4. Andersson DI, Hughes D (2014) Microbiological effects of sublethal levels of antibiotics. Nat Rev Microbiol 12:465-478. https://doi.org/10.1038/nrmicro3270

5. Baharoglu Z, Bikard D, Mazel D (2010) Conjugative DNA transfer induces the bacterial SoS response and promotes antibiotic resistance development through integron activation. PloS Genetics 6(10):e1001165. https://doi.org/10.1371/journal.pgen.1001165

6. Banuelos-Vazquez LA, Tejerizo GT, Brom S (2017) Regulation of conjugative transfer of plasmids and integrative conjugative elements. Plasmid 91:82-89.

https://doi.org/10.1016/j.plasmid.2017.04.002

7. Beaber JW, Hochhut B, Waldor MK (2004) SOS response promotes horizontal dissemination of antibiotic resistance genes. Nature 427(6969):72-74. https://doi.org/10.1038/nature02241

8. Bouma JE, Lenski RE (1988) Evolution of a bacteria/plasmid association. Nature 335(6188):351352. https://doi.org/10.1038/335351a0

9. Butala M, Zgur-Bertok D, Busby SJW (2009) The bacterial LexA transcriptional repressor. Cell Mol Life Sci 66(1):82-93. https://doi.org/10.1007/s00018-008-8378-6

10. Carlos G, Olatz G, Lur E, Elisabeth G, Itziar A (2017) Plasmid-Mediated bioaugmentation for the bioremediation of contaminated soils. Front Microbiol 8:1966.

https://doi.org/10.3389/fmicb.2017.01966

11. Chakraborty J, Das S (2016) Molecular perspectives and recent advances in microbial remediation of persistent organic pollutants. Environ Sci Pollut Res 23(17):16883-16903. https://doi.org/10.1007/s11356-016-6887-7

12. Digiovanni GD, Neilson JW, Pepper IL, Sinclair NA (1996) Gene transfer of Alcaligenes eutrophus JMP134 plasmid pJP4 to indigenous soil recipients. Appl Environ Microbiol 62(7):2521-2526. 
https://doi.org/10.1128/AEM.62.7.2521-2526.1996

13. Fan XT, Li H, Chen QL, Zhang YS, Ye J, Zhu YG, Su JQ (2019) Fate of antibiotic resistant Rseudomonas putida and broad host range plasmid in natural soil microcosms. Front Microbiol 10:194. https://doi.org/10.3389/fmicb.2019.00194

14. Fornelos N, Browning DF, Butala M (2016) The use and abuse of LexA by mobile genetic elements. Trends Microbiol 24(5):391-401. https://doi.org/10.1016/j.tim.2016.02.009

15. Guo MT, Yuan QB, Yang J (2015) Distinguishing effects of ultraviolet exposure and chlorination on the horizontal transfer on antibiotic resistance genes in municipal wastewater. Environ Sci Technol 49(9):5771-5778. https://doi.org/10.1021/acs.est.5b00644

16. Han Y, Zhou ZC, Zhu L, Wei YY, Feng WQ, Xu L, Liu Y, Lin ZJ, Shuai XY, Zhang ZJ, Chen H (2019) The impact and mechanism of quaternary ammonium compounds on the transmission of antibiotic resistance genes. Environ Sci Pollut Res 26(27):28352-28360. https://doi.org/10.1007/s11356-01905673-2

17. Herrero M, Stuckey DC (2015) Bioaugmentation and its application in wastewater treatment: A review. Chemosphere 14:119-128.

18. Ikuma K, Gunsch CK (2012a) Genetic bioaugmentation as an effective method for in situ bioremediation: Functionality of catabolic plasmids following conjugal transfers. Bioengineered 3(4):236-241. https://doi.org/10.4161/bioe.20551

19. Ikuma K, Holzem RM, Gunsch CK (2012b) Impacts of organic carbon availability and recipient bacteria characteristics on the potential for TOL plasmid genetic bioaugmentation in soil slurries. Chemosphere 89(2):158-163. https://doi.org/10.1016/j.chemosphere.2012.05.086

20. Iyer R, Aggarwal J, Iken B (2016) A review of the Texas, USA San Jacinto Superfund site and the deposition of polychlorinated dibenzo-p-dioxins and dibenzofurans in the San Jacinto River and Houston Ship Channel. Environ Sci Pollut Res 23(23):23321-23338.

https://doi.org/10.1007/s11356-016-7501-8

21. Jones C, Holland IB (1985) Role of the SuIB (FtsZ) protein in division inhibition during the SOS response in Escherichia coli: FtsZ stabilizes the inhibitor SulA in maxicells. Proc Natl Acad Sci USA 82(18):6045-6049. https://doi.org/10.1073/pnas.82.18.6045

22. Kasuga K, Nitta A, Kobayashi M, Habe H, Nojiri H, Yamane H, Omori T, Kojima I (2013) Cloning of $d f d A$ genes from Terrabactersp. strain DBF63 encoding dibenzofuran 4,4a-dioxygenase and heterologous expression in Streptomyces lividans. Appl Microbiol Biotechnol 97(10):4485-4498. https://doi.org/10.1007/s00253-012-4565-3

23. Kim D, Choi KY, Yoo M, Zylstra GJ, Kim E (2018) Biotechnological potential of Rhodococcus biodegradative pathways. J Microbiol Biotechnol 28(7):1037-1051. https://doi.org/10.4014/jmb.1712.12017

24. Kolvenbach BA, Helbling DE, Kohler HPE, Corvini PFX (2014) Emerging chemicals and the evolution of biodegradation capacities and pathways in bacteria. Curr Opin Biotechnol 27:8-14. https://doi.org/10.1016/j.copbio 
25. Kulkarni PS, Crespo JG, Afonso CAM (2008) Dioxins sources and current remediation technologies-A review. Environ Int 34(1):139-153. https://doi.org/10.1016/j.envint.2007.07.009

26. Lopatkin AJ, Sysoeva TA, You LC (2016) Dissecting the effects of antibiotics on horizontal gene transfer: Analysis suggests a critical role of selection dynamics. Bioessays 38(12):1283-1292. https://doi.org/10.1002/bies.00133

27. Lu J, Wang Y, Zhang S, Bond P, Yuan ZG, Guo JH (2020) Triclosan at environmental concentrations can enhance the spread of extracellular antibiotic resistance genes through transformation. Sci Total Environ 713:136621. https://doi.org/10.1016/j.scitotenv.2020.136621

28. Millan AS, Pena-Miller R, Toll-Riera M, Halbert ZV, McLean AR, Cooper BS, MacLean RC (2014) Positive selection and compensatory adaptation interact to stabilize non-transmissible plasmids. Nat Commun 5:5208. https://doi.org/10.1038/ncomms6208

29. Millan AS, Maclean RC (2017) Fitness Costs of plasmids: a limit to plasmid transmission. Microbiology Spectrum 5(5):1-12. https://doi.org/10.1128/microbiolspec.MTBP-0016-2017

30. Monika S, Himani K, Narain SD, Krishan NR (2021) The genus Sphingopyxis: Systematics, ecology, and bioremediation potential-A review. J Environ Manage 280:111744. https://doi.org/10.1016/j.jenvman.2020.111744

31. Peng P, Yang HY, Jia RB, Li L (2013) Biodegradation of dioxin by a newly isolated Rhodococcus sp. with the involvement of self-transmissible plasmids. Appl Microbiol Biotechnol 97(12):5585-5595. https://doi.org/10.1007/s00253-012-4363-y

32. Popa O, Dagan T (2011) Trends and barriers to lateral gene transfer in prokaryotes. Curr Opin Microbiol 14(5):615-623. https://doi.org/10.1016/j.mib.2011.07.027

33. Pu Q, Fan XT, Li H, An XL, Lassen SB, Su JQ (2021) Cadmium enhances conjugative plasmid transfer to a fresh water microbial community. Environ Pollut 268:115903.

https://doi.org/10.1016/j.envpol.2020.115903

34. Qiu ZG, Yu YM, Chen ZL, Jin M, Yang D, Zhao ZG, Wang JF, Shen ZQ, Wang XW, Qian D, Huang AH, Zhang BC, Li JW (2012) Nanoalumina promotes the horizontal transfer of multiresistance gene mediated by plasmids across genera. Proc Natl Acad Sci USA 109(13):4944-4949. https://doi.org/10.1073/pnas.1107254109

35. Ren CY, Wang YY, Tian LL, Chen M, Sun J, Li L (2018) Genetic bioaugmentation of activated sludge with dioxin-catabolic plasmids harbored by Rhodococcus sp strain p52. Environ Sci Technol 52(9):5339-5348. https://doi.org/10.1021/acs.est.7b04633

36. Sharma JK, Gautam RK, Nanekar SV, Weber R, Singh BK, Singh SK, Juwarkar AA (2018) Advances and perspective in bioremediation of polychlorinated biphenyl contaminated soils. Environ Sci Pollut Res 25(17):16355-16375. https://doi.org/10.1007/s11356-017-8995-4

37. Shintani M, Matsui K, Inoue J, Hosoyama A, Ohji S, Yamazoe A, Nojiri H, Kimbara K, Ohkuma M (2014) Single-Cell analyses revealed transfer ranges of IncP-1, IncP-7, and IncP-9 plasmids in a soil bacterial community. Appl Environ Microbiol 80(1):138-145. https://doi.org/10.1128/AEM.02571-13 
38. Shintani M, Ohkuma M, Kimbara K (2018) High-resolution comparison of bacterial conjugation frequencies. JOVE-Journal of Visualized Experiments 143:e57812. https://doi.org/10.3791/57812

39. Stallwood B, Shears J, Williams PA, Hughes KA (2005) Low temperature bioremediation of oil contaminated soil using biostimulation and bioaugmentation with a Pseudomonas sp. from maritime Antarctica. J Appl Microbiol 99(4):794-802. https://doi.org/10.1111/j.13652672.2005.02678.x

40. Sun J, Qiu YL, Ding PF, Peng P, Yang HY, Li L (2017) Conjugative transfer of dioxin-catabolic megaplasmids and bioaugmentation prospects of a Rhodococcus sp. Environ Sci Technol 51(11):6298-6307. https://doi.org/10.1021/acs.est.7b00188

41. Suzuki H, Yano H, Brown CJ, Top EM (2010) Predicting plasmid promiscuity based on genomic signature. J Bacteriol 192(22):6045-6055. https://doi.org/10.1128/JB.00277-10

42. Top EM, Springael D, Boon N (2002) Catabolic mobile genetic elements and their potential use in bioaugmentation of polluted soils and waters. FEMS Microbiol Ecol 42(2):199-208. https://doi.org/10.1016/S0168-6496(03)00034-5

43. Top EM, Springael D (2003) The role of mobile genetic elements in bacterial adaptation to xenobiotic organic compounds. Curr Opin Biotechnol 14(3):262-269. https://doi.org/10.1016/S09581669(03)00066-1

44. Tsuda M, Tan HM, Nishi A, Furukawa K (1999) Mobile catabolic genes in bacteria. J Biosci Bioeng 87(4):401-410. https://doi.org/10.1016/S1389-1723(99)80086-3

45. Urban JD, Wikoff DS, Bunch ATG, Harris MA, Haws LC (2014) A review of background dioxin concentrations in urban/suburban and rural soils across the United States: Implications for site assessments and the establishment of soil cleanup levels. Sci Total Environ 466:586-597. https://doi.org/10.1016/j.scitotenv.2013.07.065

46. Van DMJR, Ravatn R, Sentchilo V (2001) The clc element of Pseudomonas sp. strain B13 and other mobile degradative elements employing phage-like integrases. Arch Microbiol 175(2):79-85. https://doi.org/10.1007/s002030000244

47. Van LMCM, Nielsen PH, Lopez-vazquez CM, Brdjanovic D (2016) Experimental Methods in Wastewater Treatment. IWA publishing, London

48. Wang Y, Lu J, Mao LK, Li J, Yuan ZG, Bond PL, Guo JH (2018) Antiepileptic drug carbamazepine promotes horizontal transfer of plasmid-borne multi-antibiotic resistance genes within and across bacterial genera. The ISME Journal 13(2):509-522. https:// doi.org/10.1038/s41396-018-0275-x

49. Wang S, Li SS, Du D, Wang D, Yan W (2020) Conjugative transfer of Megaplasmids pND6-1 and pND6-2 enhancing naphthalene degradation in aqueous environment: characterization and bioaugmentation prospects. Applied Microbiology and Biotechnology 104:861-871. https://doi.org/104:861-871

50. Yun JJ, Heisler LE, Hwang II, Wilkins O, Lau SK, Hyrcza M, Jayabalasingham B, Jin J, McLaurin J, Tsao MS, Der SD (2006) Genomic DNA functions as a universal external standard in quantitative real-time PCR. Nucleic Acids Res 34(22):6718-6718. https://doi.org/10.1093/nar/gkl400 
51. Zhang Y, Gu AZ, Cen TY, Li XY, He M, Li D, Chen JM (2018) Sub-inhibitory concentrations of heavy metals facilitate the horizontal transfer of plasmid mediated antibiotic genes in water environment. Environ Pollut 237:74-82. https://doi.org/10.1016/j.envpol.2018.01.032

52. Zhang S, Wang Y, Song HL, Lu J, Yuan ZG, Guo JH (2019) Copper nanoparticles and copper ions promote horizontal transfer of plasmid-mediated multi-antibiotic resistance genes across bacterial genera. Environ Int 129:478-487. https://doi.org/10.1016/j.envint.2019.05.054

53. Zhao JG, Li YH, Li Y, Yang HJ, Hu DH, Zhang HZ (2019) Effects of 4-chlorophenol toxicity on sludge performance and microbial community in sequencing batch reactors. Journal of Environmental Science Health Part A-Toxic/Hazardous Substances Environmental Engineering 54(6):498-505. https://doi.org/10.1080/10934529.2019.1567159

\section{Figures}
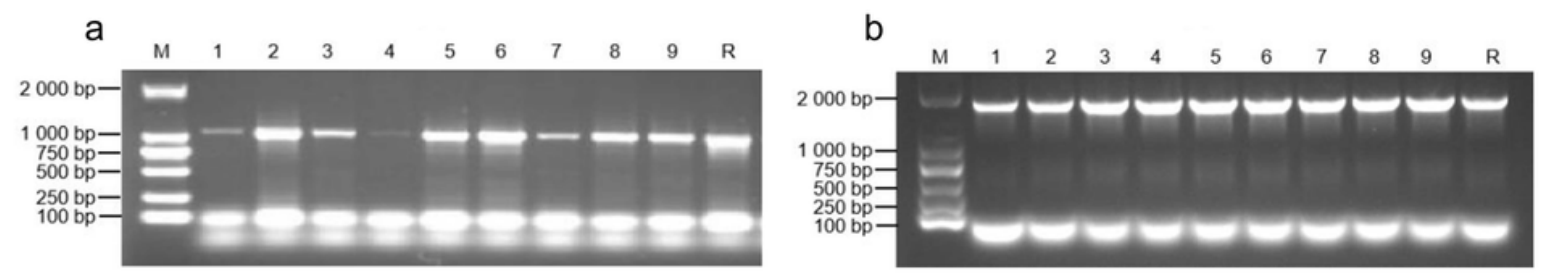

\section{Figure 1}

Confirmation of transconjugants by PCR. (a) The amplification product targeting the angular dioxygenase gene dfdA1 (1.07 kb) located on pDF01. (b) The amplification product targeting the angular dioxygenase gene dbfA1(1.80 kb) located on pDF02. DNA Maker is shown in Lane $M$, and transconjugant candidates are shown in Lanes 1-9. Lane $\mathrm{R}$ is the amplification result of Rhodococcus sp. strain p52 as a positive control 


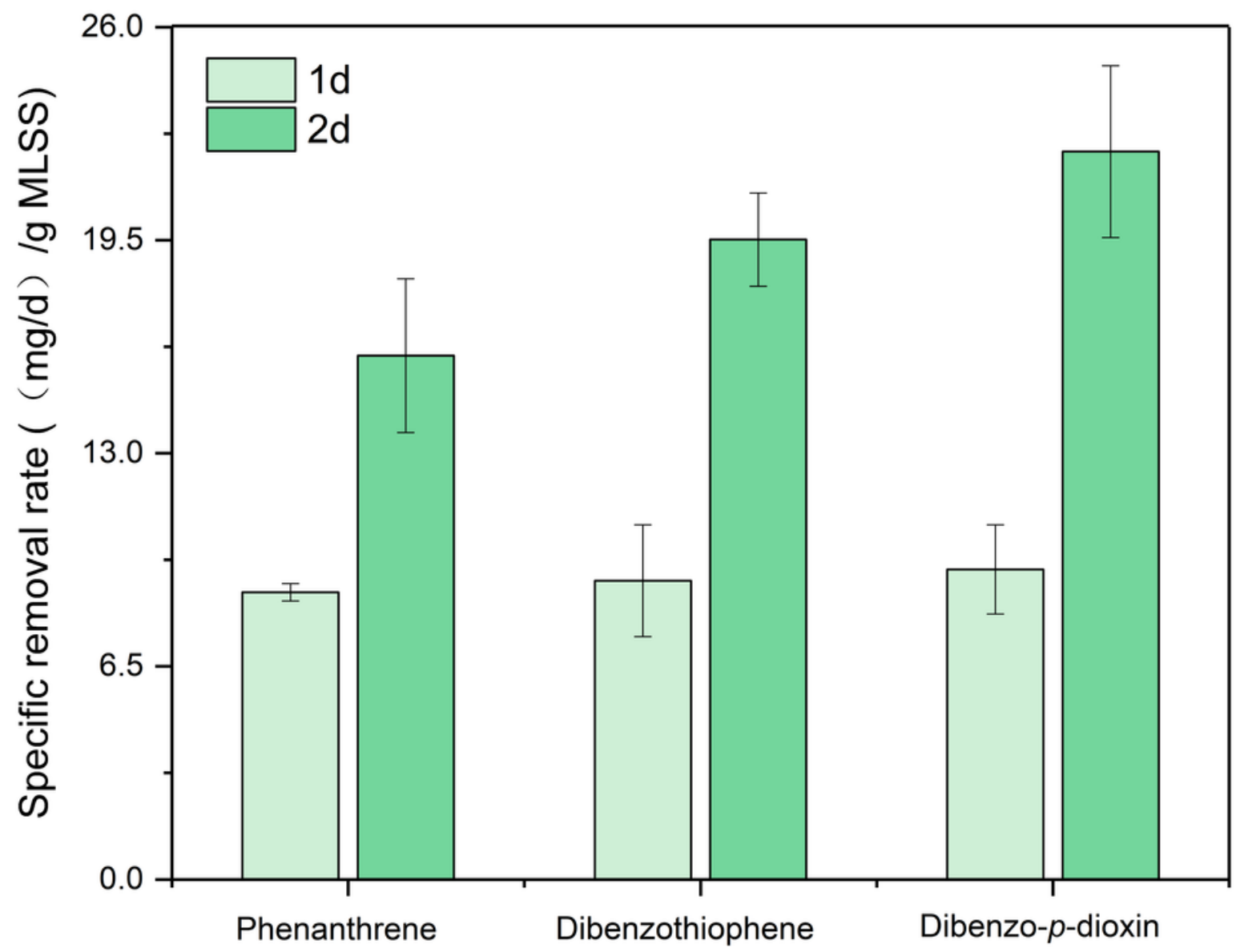

Figure 2

Specific removal rates of the contaminants by the activated sludge bioaugmented with Rhodococcus sp. strain p52 

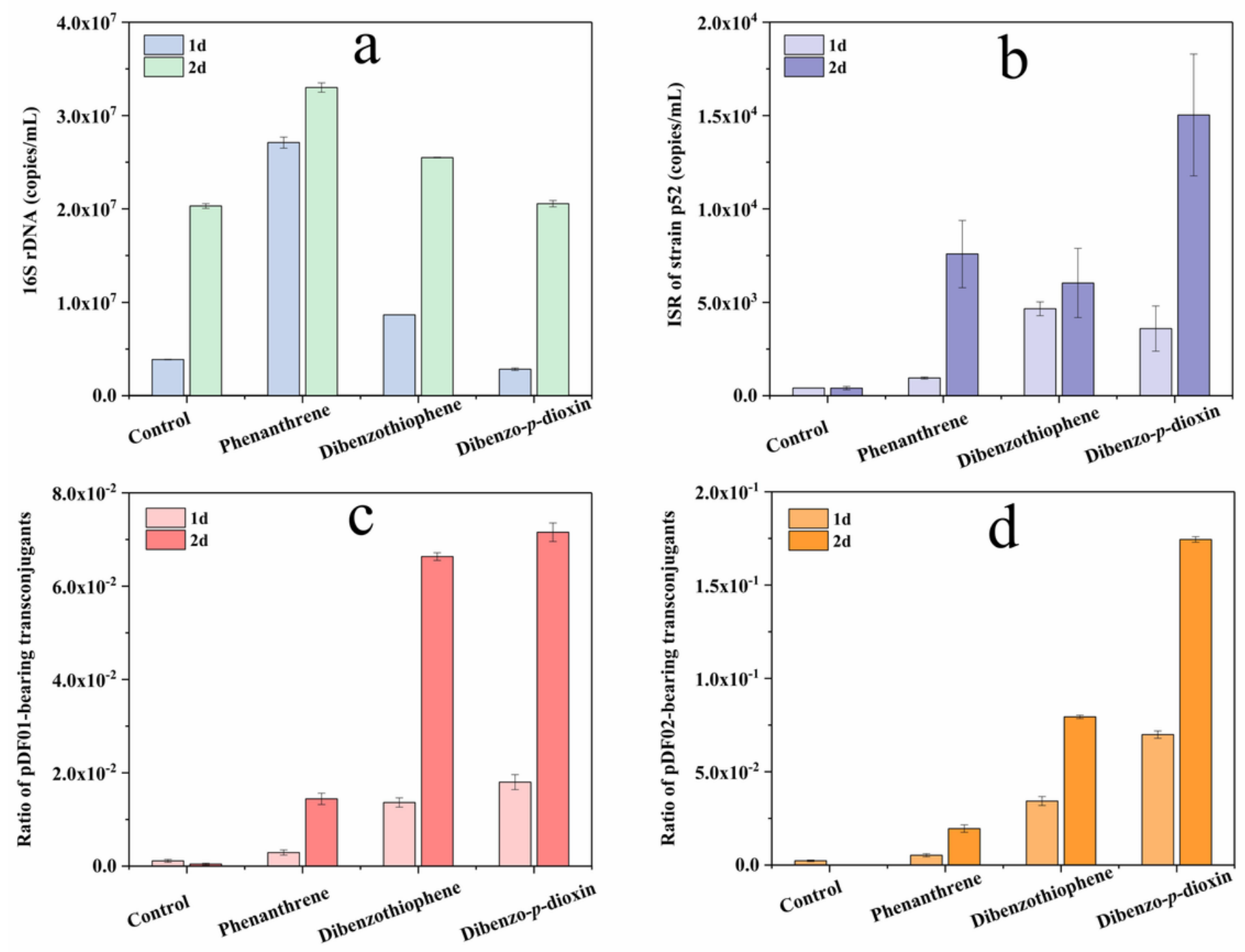

Figure 3

Effects of different contaminants on the amount of sludge bacteria, Rhodococcus sp. strain p52, and transconjugants in the activated reactors. The copy numbers of the 16S rDNA and strain p52 ISR fragment in reactors fed with different contaminants detected by qPCR are shown in a and b, respectively. The ratios of pDF01- and pDF02-bearing transconjugants in the reactors detected by qPCR are shown in $\mathrm{c}$ and $d$, respectively 

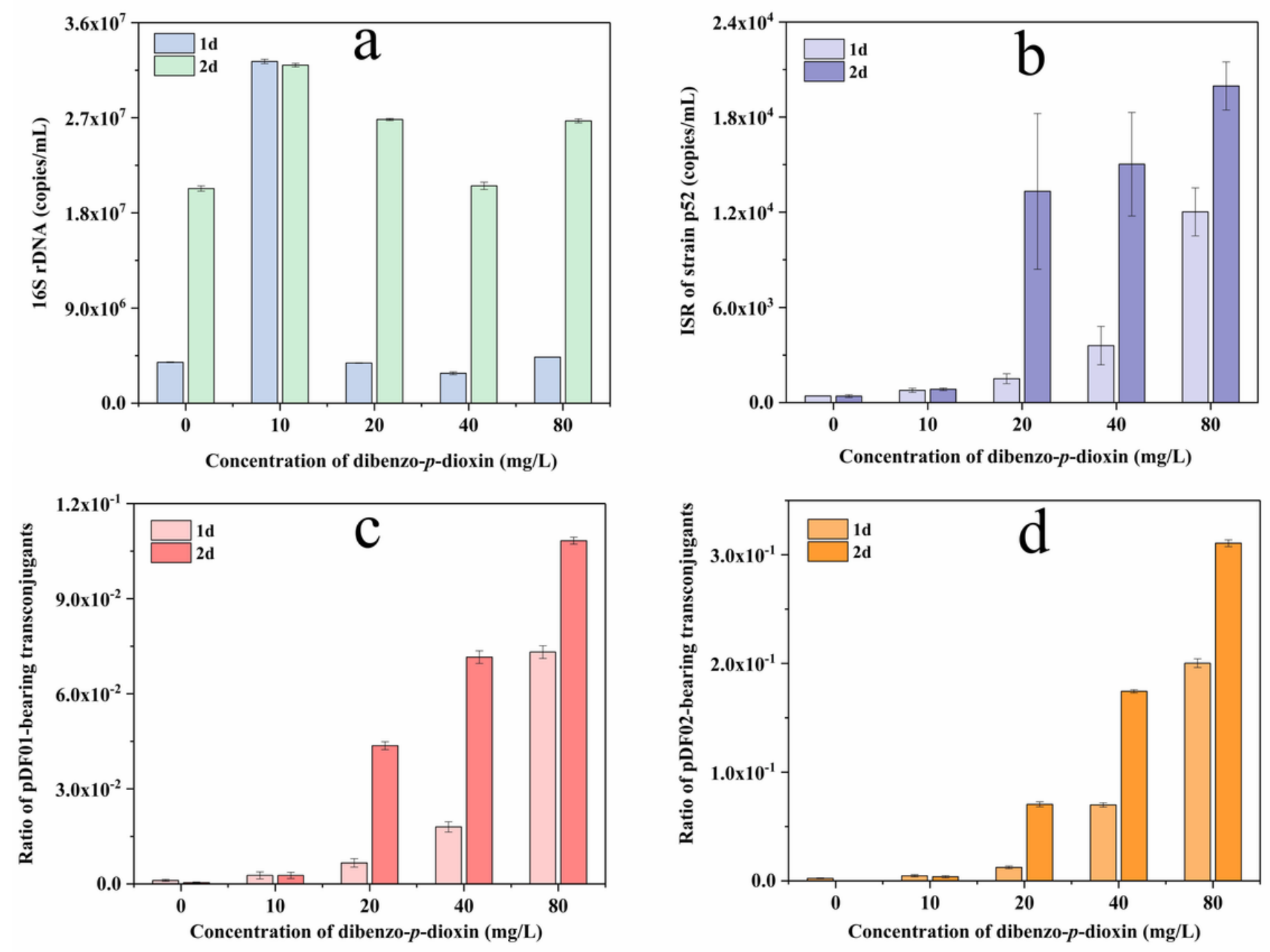

Figure 4

Effects of dibenzo-p-dioxin at different concentrations on the amount of sludge bacteria, Rhodococcus sp. strain p52, and transconjugants in the activated reactors. The copy numbers of the16S rDNA and strain p52 ISR fragment in reactors fed with dibenzo-p-dioxin detected by qPCR are shown in a and b, respectively. The ratios of pDF01- and pDF02-bearing transconjugants in the reactors detected by qPCR are shown in c and d, respectively 

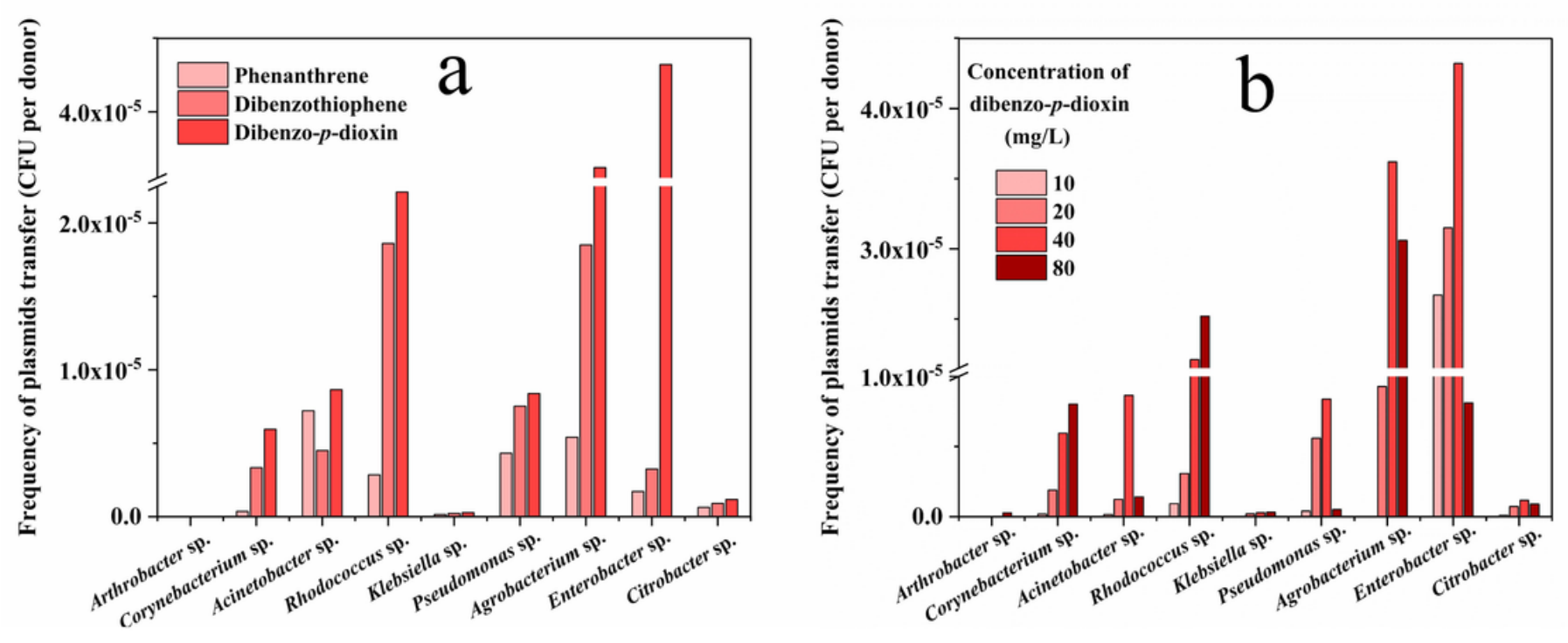

Figure 5

Influence of the recipients on the catabolic plasmid transfer under contaminant stress. Frequencies of the plasmids transferred between strain p52 and different recipients by film mating tests under different contaminant stresses and under dibenzo-p-dioxin at different concentrations are shown in a and b, respectively

\section{Supplementary Files}

This is a list of supplementary files associated with this preprint. Click to download.

- renamed688f1.docx 